\title{
Bacterial Community of the Rice Floodwater Using Cultivation-Independent Approaches
}

\author{
Michele Pittol D, ${ }^{1}$ Erin Scully, ${ }^{2}$ Daniel Miller, ${ }^{3}$ Lisa Durso, ${ }^{3}$ \\ Lidia Mariana Fiuza, ${ }^{1}$ and Victor Hugo Valiati ${ }^{1}$ \\ ${ }^{1}$ Programa de Pós-Graduação em Biologia, Universidade do Vale do Rio dos Sinos (UNISINOS), 950 Unisinos Avenue, \\ São Leopoldo, RS, Brazil \\ ${ }^{2}$ United States Department of Agriculture (USDA), Agricultural Research Service (ARS), Center for Grain and Animal Health Research, \\ Stored Product Insect and Engineering Research Unit (SPIERU), 1515 College Ave., Manhattan, KS, USA \\ ${ }^{3}$ United States Department of Agriculture (USDA), Agricultural Research Service (ARS), \\ Agroecosystem Management Research Unit (AMRU), 251 Filley Hall, UNL East Campus, Lincoln, NE, USA
}

Correspondence should be addressed to Michele Pittol; mipittoll@gmail.com

Received 2 August 2017; Revised 9 December 2017; Accepted 26 December 2017; Published 30 January 2018

Academic Editor: Clemencia Chaves-López

Copyright (C) 2018 Michele Pittol et al. This is an open access article distributed under the Creative Commons Attribution License, which permits unrestricted use, distribution, and reproduction in any medium, provided the original work is properly cited.

\begin{abstract}
In agricultural systems, interactions between plants and microorganisms are important to maintaining production and profitability. In this study, bacterial communities in floodwaters of rice fields were monitored during the vegetative and reproductive stages of rice plant development using $16 \mathrm{~S}$ amplicon sequencing. The study was conducted in the south of Brazil, during the crop years 2011/12 and 2012/13. Comparative analyses showed strong differences between the communities of floodwaters associated with the two developmental stages. During the vegetative stage, 1551 operational taxonomic units (OTUs) were detected, while less than half that number (603) were identified in the reproductive stage. The higher bacterial richness observed in floodwater collected during the vegetative stage may have been favored by the higher concentration of nutrients, such as potassium, due to rhizodeposition and fertilizer application. Eighteen bacterial phyla were identified in both samples. Both communities were dominated by Gammaproteobacteria. In the vegetative stage, Alphaproteobacteria and Betaproteobacteria were more abundant and, in contrast, Bacilli and Clostridia were the more dominant classes in the reproductive stage. The major bacterial taxa identified have been previously identified as important colonizers of rice fields. The richness and composition of bacterial communities over cultivation time may contribute to the sustainability of the crop.
\end{abstract}

\section{Introduction}

Rice (Oryza sativa L.) is the most important cereal crop in the world, feeding more than $50 \%$ of the human population. In South America, Brazil is the main producer [1], with flooded rice fields accounting for $50 \%$ of the total crop area under cultivation in the country [2]. In flooded rice, the need to maintain adequate water depth throughout most of the crop year characterizes the agricultural system as aquatic in nature. In comparison to other aquatic environments, such as lakes, ponds, and swamps, the environmental conditions in flooded rice fields are relatively unstable due to physical and chemical and biological characteristics that vary according to current agricultural practices and water supplies [3]. The varying physical and chemical properties in this environment could support the growth of microorganisms possessing wide ranges of metabolic plasticity, allowing them to quickly adapt to changing environmental conditions [4]. Thus, the rice ecosystem may be a prime habitat for microorganisms adapted to fluctuating nutritional levels and oxygen and light availability.

The phyla Acidobacteria, Actinobacteria, Bacteroidetes, Chloroflexi, and Proteobacteria have been previously found in soil samples of rice-alfalfa [5] and rice-wheat cropping [6]. In these agroecosystems, rice exudates and nutrients from straw incorporation were shown to influence the bacterial community's composition. Breidenbach and Conrad [7] found a uniform bacterial composition in soil over the 
rice growing season, with Proteobacteria being the most highly abundant phylum, while Firmicutes represented the fifth most abundant phylum. Firmicutes were also present in relatively low abundance upon the introduction of a maize rotation into an irrigated rice field [8]. Although these microorganisms are common inhabitants of agriculture soils, the low counts of Firmicutes are intriguing considering that this group contains the classes Bacilli and Clostridia, which are often highly abundant in rice agricultural soils where they decompose plant residues using cellulolytic enzymes [9]. Furthermore, the researchers observed higher bacterial 16S rRNA abundance in the flooding stage than in drainage stage, which was ascribed to the rice straw that remained in the field [10].

In the studies mentioned above, the shifts in microbial community structure were governed by environmental factors found in rice fields. These factors can be related to the input of nutrients from water sources, rice residues, and fertilizers, weather conditions, and crop rotation, highlighting the complex network of elements that govern bacterial structure in this agricultural system. Although microbial ecology studies in soil, rhizosphere, and endophytic environments have been previously conducted in rice systems [1114], the dynamics of bacterial communities in floodwaters from rice fields have not been extensively studied despite the important roles of the floodwaters and microbial communities in rice plant nutrition [15]. Because microbes can contribute strongly to rice nutrition and production, there is much interest in surveying the microbial communities in this flooded agroecosystem and determining how agricultural practices influence the composition and structure of these communities [16]. The purpose of the present study was to investigate the bacterial community structure and composition in floodwaters associated with vegetative and reproductive stages of rice in order to verify if there is a microbial community related to a particular stage of the rice system.

\section{Materials and Methods}

2.1. Study Area and Sampling Protocols. Three isolated flooded rice fields were selected for this study. The rice fields were between 164 and 310 ha in area and are located in the city of Viamão $\left(30^{\circ} 04^{\prime} 51^{\prime \prime} \mathrm{S}, 51^{\circ} 01^{\prime} 22^{\prime \prime} \mathrm{W}\right)$, outer coastal plain, Rio Grande do Sul (RS), Brazil, Figure 1.

Twelve water samples were collected from the three locations above in the agricultural years 2011/12 and 2012/13, six in the vegetative and six in the reproductive stages. One sample from each location and developmental stage was collected during the 2011/12 growing season and another sample was collected during the 2012/13 growing season. The collections were organized as follows: the vegetative (tillering) (October/November) stage was defined by active tillering and coleoptile and radicle $(2-3 \mathrm{~mm})$ formation to the beginning of panicle differentiation, while the reproductive stage was defined from the formation until complete maturation of the panicle (December to March) [17]. Each of the 12 individual water samples collected represented a combination of 16 subsamples of $50 \mathrm{~mL}$ collected from the top surface of the floodwater to $10 \mathrm{~cm}$ in depth [18], thereby maximizing the search for the richness and abundance of the local microbiota. Afterwards, the 16 subsamples from each stage within a location were combined into a single composite water sample of $800 \mathrm{~mL}$ for DNA isolation. The 12 samples representing two life stages from three different locations were centrifuged at $12,000 \times \mathrm{g}$ for $15 \mathrm{~min}$ at $4^{\circ} \mathrm{C}$ and the pellets were stored at $-20^{\circ} \mathrm{C}$ for subsequent DNA extraction and analysis.

2.2. DNA Extraction and Pyrosequencing. Total DNA was extracted from each of the 12 pellets collected from the floodwater samples from two life stages at three locations using the MoBio Power Soil ${ }^{\circledR}$ DNA Isolation Kit (MoBio, Laboratories Inc., Carlsbad, CA, USA) following the manufacturer's instructions. The DNA yield was measured using a NanoDrop ${ }^{\circledR}$ ND-1000 spectrophotometer (NanoDrop Technologies, Inc. Wilmington, DE, USA) and the DNA quality was verified on a $1.5 \%$ agarose gel stained with ethidium bromide $\left(0.1 \mathrm{mg} \mathrm{mL}^{-1}\right)$.

Purified DNA from the six replicates collected during the vegetative stage and the six replicates collected during the reproductive stage were pooled together to create a single DNA pool for the vegetative samples and a single DNA pool for the reproductive samples. These two DNA pools (one DNA pool from vegetative samples and one DNA pool from reproductive samples) were used as templates for amplicon pyrosequencing analysis, which was performed by MR DNA Laboratory (Shallow Water, TX, USA), with the goal of investigating the bacterial community structure and composition. The $\mathrm{V} 1-\mathrm{V} 3$ variable regions of the $16 \mathrm{~S}$ rRNA gene were amplified using primers ill27Fmod $\left(5^{\prime}\right.$ AGRGTTTGATCMTGGCTCAG- $\left.3^{\prime}\right)$ and ill519Rmod $\left(5^{\prime}\right.$ GTNTTACNGCGGCKGCTG-3') [19]. The PCR reactions were prepared with $1 \mu \mathrm{L}$ of DNA ( $\left.5 \mathrm{ng} \mu \mathrm{L}^{-1}\right)$ using HotStarTaq Plus Master Mix (Qiagen, Valencia, CA, USA). DNA was initially denatured at $94^{\circ} \mathrm{C}$ for $3 \mathrm{~min}$ followed by 28 cycles of $94^{\circ} \mathrm{C}$ for $30 \mathrm{~s} ; 53^{\circ} \mathrm{C}$ for $40 \mathrm{~s}$ and $72^{\circ} \mathrm{C}$ for $1 \mathrm{~min}$; and a final extension at $72^{\circ} \mathrm{C}$ for $5 \mathrm{~min}$. PCR products of approximately 300 bp were purified using Agencourt Ampure beads (Agencourt Bioscience Corporation, MA, USA). The amplicons were sequenced using 454 GS FLX Titanium chemistry (Roche) following the manufacturer's guidelines. The raw 454 reads generated during the current study have been deposited in NCBI's Sequence Read Archive (SRA) under the accession SRP077313 and are associated with BioProject PRJNA326968.

\subsection{Protocols and Equipment Used for the Physicochemical} Measurements of Water. Water parameters such as temperature, turbidity, and $\mathrm{pH}$ were measured from all 12 samples using the Intelligent Meter equipment (INSTRUTHERM PH1300). In addition, nutrient levels, including total phosphorus (P) and potassium (K), were measured from each of the six water samples collected from the two developmental stages using standard methods [18]. The available $\mathrm{P}$ and $\mathrm{K}$ were determined using Mehlich-1 solution by molecular colorimetric and flame emission methods, respectively [20, 21].

2.4. Data Analysis. The 454 amplicon data from bacterial communities sampled from floodwaters from the reproductive $(n=1)$ and vegetative $(n=1)$ stages were analyzed using 


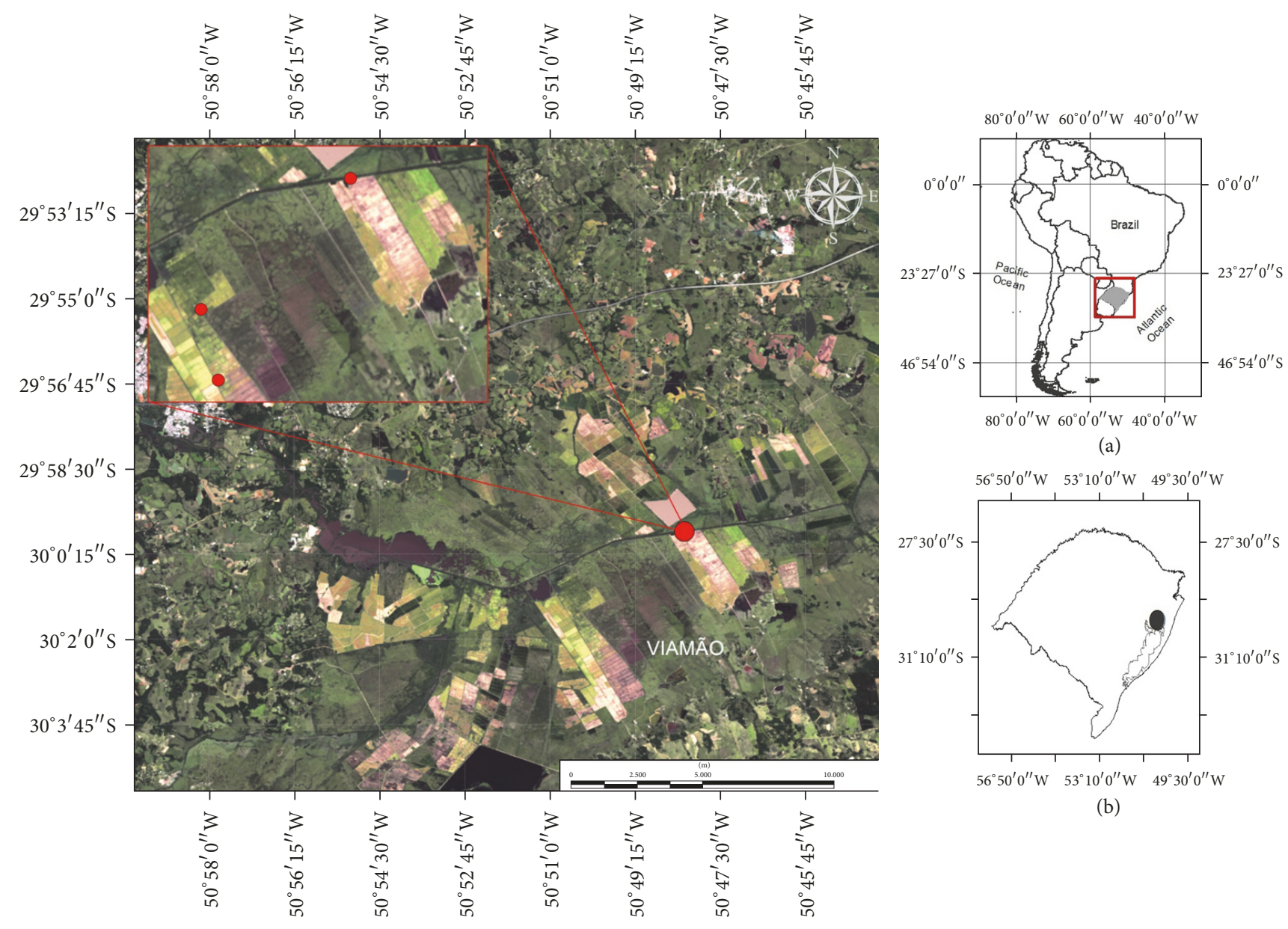

(c)

Figure 1: (a) Location of Rio Grande do Sul state, Southern of Brazil. (b) Viamão city, outer coastal plain of Rio Grande do Sul state; (c) study area with the three sampling sites in the flooded rice fields.

the mothur pipeline (version 1.32.1) [22]. In brief, flowgrams were demultiplexed using the trim.flows command and denoised using the shhh.flows command, which is the mothur implementation of PyroNoise [23]. In addition, adapters, barcodes, primers, short reads, and reads containing more than eight homopolymer bases were removed from the dataset with trim.seqs command. Cleaned sequences were aligned to the Silva reference database [24] using the Needleman aligner with the align.seqs command. Chimeric sequences were flagged and removed from the dataset using the uchime algorithm with the reference=self-flag [25]. Then, the remaining high quality sequences were taxonomically classified using the Wang method of the classify.seqs command and the Silva reference taxonomy files. An $80 \%$ confidence score was required for all taxonomic assignments. Amplicons classified as mitochondrial, chloroplast, Archaeal, eukaryotic, or unknown in origin were removed from the dataset.

The remaining bacterial sequences were categorized into operational taxonomic units (OTUs) at 3\% sequence dissimilarity using the average neighbor algorithm. The consensus taxonomy for each OTU was determined using the classify.otu command. Rarefaction curves were calculated using the rarefaction.single command at a genetic distance of 0.03 , while the summary.single command was used to compute various community metrics including the Shannon-Wiener $\left(\mathrm{H}^{\prime}\right)$ and Simpson indices, the Chao 1 richness estimator [26], which estimates species richness based on the number of rare OTUs detected in each community, and the Abundance Coverage-based Estimator (ACE), which estimates the number of undetected OTUs based on the abundance and distribution of rare OTUs. Prior to computing rarefaction curves and community diversity/richness metrics, the same number of reads $(7,348)$ were subsampled without replacement from each of the libraries for normalization and to prevent differences in library yields from driving differences between the two communities. The mothur command Libshuff was used to determine whether the bacterial communities from the vegetative and reproductive stages have the same structure with iters set to 1000 .

Heatmaps and cluster dendrograms based on Euclidean dissimilarity metrics were built according to the relative 


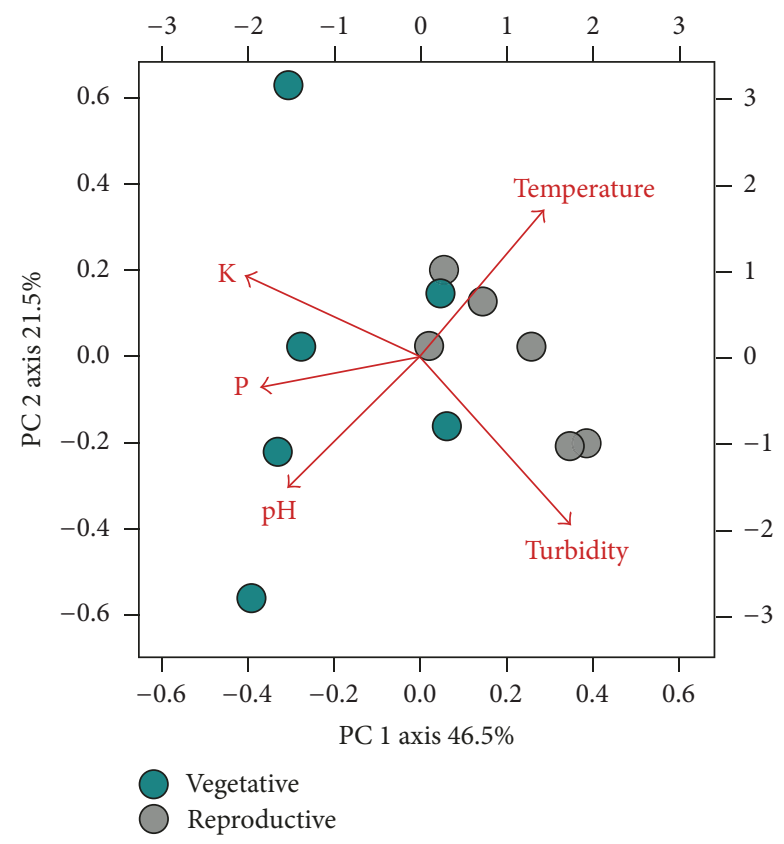

FIGURE 2: PCA biplot of physical and chemical parameters sampled from rice floodwaters from vegetative and reproductive stages.

abundances of the most common genera in the two communities using the "vegan," "heatmap.2," and "cluster" packages [27] in the R statistical computing environment (version 3.1.0). To select the most abundant genera, reads counts for all OTUs assigned to the same genus from both samples were summed together, normalized by relative abundance, and ranked in ascending order. The relative abundances of these genera in floodwaters associated with each developmental stage were $\log _{2}$ transformed, $z$-scale standardized, and used for clustering and heatmap analysis. Venn diagrams depicting OTUs found in floodwaters from both developmental stages and and OTUs unique to each developmental stage were constructed using the venn command in mothur.

The physical and chemical characteristics of the floodwater from the rice fields sampled during two agricultural years were analyzed by principal components analysis (PCA) using the following variables: temperature $\left({ }^{\circ} \mathrm{C}\right)$, turbidity (NTU), $\mathrm{pH}$, total phosphorus $(\mathrm{P})\left(\mathrm{mg} \mathrm{L}^{-1}\right)$, and potassium (K) $\left(\mathrm{mg} \mathrm{L}^{-1}\right)$. Prior to analysis, all variables were $\log _{10}$ transformed in order to facilitate comparisons among variables expressed in different units. The correlation matrix with the varimax rotation was set and only autovalues greater than 1 were utilized as criteria for extraction of the principal components. The analysis was performed in the $\mathrm{R}$ statistical computing environment (version 3.1.0) using the princomp and biplot functions. The differences among physicochemical parameters between the rice stages were tested using Student's $t$-test in SYSTAT 12 (Systat Software, Inc., CA, USA). $p$ values of $<0.05$ were considered statistically significant.

\section{Results}

3.1. Physical and Chemical Characteristics of Rice Field Water. Principal components analysis was used to monitor the physical and chemical variations of floodwater of rice fields in vegetative and reproductive stage of two consecutive agricultural years. The physical and chemical patterns of floodwater retrieved from the vegetative and reproductive rice stages are shown in Figure 2.

The first two principal components explained a combined total of $68 \%$ of the total variance. Most water samples collected from the vegetative stage were separated from the reproductive stage samples along the $\mathrm{PCl}$ axis. No major differences between locations or agricultural years were noted. In general, vegetative stage samples tended to have higher levels of $\mathrm{pH}, \mathrm{K}$, and $\mathrm{P}$ compared to the reproductive samples. In contrast, the reproductive samples tended to be more turbid and had higher temperatures compared to the vegetative samples. In addition, some variability was apparent within the water samples collected from each developmental stage, which is likely reflective of the dynamic nature of the physical and chemical variables in rice floodwaters (Figure 2). Temperature and $\mathrm{K}$ differed significantly between the two rice development stages. Specifically, the temperature was on average three degrees warmer in floodwaters associated with the reproductive stage. $\mathrm{K}$ was almost four times higher in the vegetative compared to the reproductive stage (Table 1).

\subsection{Composition of the Bacterial Community in Floodwaters} over Two Stages of Rice Growth. The pyrosequencing-based analysis generated 25,981 amplicons from the vegetative stage samples and 18,849 amplicons from the reproductive stage samples. After quality filtering and dereplication of identical sequences, 8,483 reads were retained from the water samples collected during vegetative stage and 7,348 reads were retained from samples collected during the reproductive stage. For normalization purposes, 7,348 reads were randomly subsampled without replacement from the vegetative library prior to OTU analysis and taxonomic classification.

The structures of the bacterial community differed significantly between the vegetative and reproductive stages of flooded rice $(p=0,0001)$ using Libshuff. In the vegetative stage, 1,551 OTUs were identified, while less than half the number of OTUs (603) were detected in water samples collected from the reproductive stage (Table 2). Further, only $88(4.08 \%)$ of the OTUs detected in this analysis were common to both crop stages, possibly reflecting the dynamic structure of the bacterial communities associated with this environment (Figure 3).

The sequences were distributed among 18 different bacterial phyla. The most species-rich phyla in both the reproductive and vegetative stages were Proteobacteria, which contained $53.34 \%$ of the OTUs detected in both samples, Bacteroidetes (16.80\% of the OTUs), Actinobacteria (7.84\%), and Firmicutes (5.52\%). In total, $83.50 \%$ of the total OTUs detected in these two communities was associated with these four phyla. Several phyla with lower richness estimates were also detected in these samples, defined as phyla containing less than $1 \%$ of the total OTUs detected in this analysis. Based on this criterion, a total of twelve rare phyla were detected including Chloroflexi, Deferribacteres, Deinococcus-Thermus, Fusobacterium, Gemmatimonadetes, OP10, Planctomycetes, SR1, Spirochaetes, TM7, 
TABLE 1: Mean values and corresponding standard deviations, for the physicochemical parameters measured in the water samples in relation to the rice stages.

\begin{tabular}{|c|c|c|c|c|c|c|}
\hline Rice stages & & Temperature ${ }^{*}\left({ }^{\circ} \mathrm{C}\right)$ & $\mathrm{pH}$ & Turbidity (NTU) & Total P $(\mathrm{mg} / \mathrm{L})$ & Total K $(\mathrm{mg} / \mathrm{L})^{*}$ \\
\hline \multirow{7}{*}{ Vegetative } & & 30.20 & 6.50 & 4.30 & 0.65 & 14.70 \\
\hline & & 24.06 & 6.21 & 34.16 & 0.44 & 31.75 \\
\hline & & 22.73 & 7.43 & 68.83 & 0.84 & 12.34 \\
\hline & & 29.40 & 6.70 & 39.86 & 0.01 & 11.77 \\
\hline & & 23.60 & 6.50 & 37.56 & 0.02 & 4.29 \\
\hline & & 27.20 & 7.43 & 42.20 & 1.30 & 11.59 \\
\hline & Mean \pm SD & $26.20 \pm 3.18$ & $6.80 \pm 0.51$ & $37.82 \pm 20.60$ & $0.54 \pm 0.49$ & $14.41 \pm 9.19$ \\
\hline \multirow{7}{*}{ Reproductive } & & 28.70 & 6.17 & 108.00 & 0.05 & 4.50 \\
\hline & & 31.30 & 6.70 & 41.80 & 0.05 & 4.20 \\
\hline & & 27.30 & 6.20 & 253.20 & 0.01 & 1.89 \\
\hline & & 29.20 & 6.43 & 93.10 & NA & 6.10 \\
\hline & & 29.60 & 6.50 & 27.55 & 0.17 & 5.04 \\
\hline & & 30.80 & 6.50 & 391.00 & 0.14 & 1.62 \\
\hline & Mean \pm SD & $29.48 \pm 1.44$ & $6.42 \pm 0.20$ & $152.44 \pm 141.70$ & $0.08 \pm 0.06$ & $3.89 \pm 1.77$ \\
\hline
\end{tabular}

NA: not available; SD: standard deviation; * means differed significantly $(p<0.05)$.

TABLE 2: Richness estimators (Chao 1 and Ace) and diversity indices of Shannon-Wiener $\left(\mathrm{H}^{\prime}\right)$ and Simpson from bacterial communities sampled from floodwaters during reproductive and vegetative stages of rice using $16 \mathrm{~S}$ amplicons. A $3 \%$ nucleotide dissimilarity was used for OTU discrimination.

\begin{tabular}{lcccccccc}
\hline \multirow{2}{*}{ Crop stage } & \multicolumn{3}{c}{ Number of sequences } & \multicolumn{3}{c}{$3 \%$ divergence } \\
& Raw sequences & Analysed sequences & Normalization & OTUs & Chao 1 & Ace & Shannon-Wiener $\left(\mathrm{H}^{\prime}\right)$ & Simpson \\
\hline Vegetative & 25,981 & 8,483 & 7,348 & 1,551 & 2,282 & 2,266 & 5.77 & 0.03 \\
Reproductive & 18,849 & 7,348 & 7,348 & 603 & 822 & 842 & 4.28 & 0.05 \\
\hline
\end{tabular}

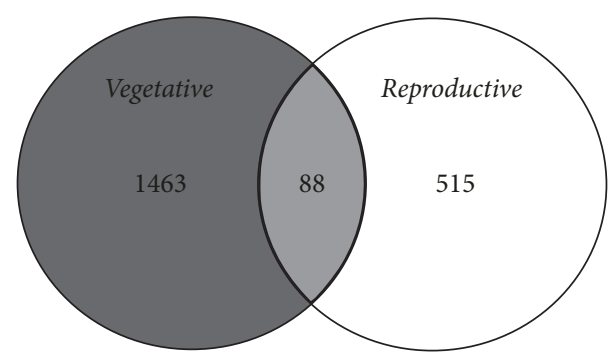

FIGURE 3: Venn diagram of $16 \mathrm{~S}$ OTUs shared and unique to floodwater samples collected from vegetative and reproductive stages of rice plants. Sequences were classified into OTUs at $97 \%$ similarity using the average neighbor algorithm in mothur.

Tenericutes, and Verrucomicrobia, which were detected in both stages of crop development. The phyla Acidobacteria (1.94\% of the OTUs) and Cyanobacteria (1.25\%) were also present, but at low frequencies ( $\leq 2 \%$ of the OTUs).

In total, 27 different bacterial classes were identified in both developmental stages. In general, the class level abundances of the 88 OTUs shared between the floodwaters from the vegetative and reproductive stages were very similar and were both dominated by Betaproteobacteria, Actinobacteria, and Alphaproteobacteria (Figures 4(a) and 4(b)). In contrast, the class level distributions of OTUs unique to floodwaters sampled from either the vegetative or reproductive stages were drastically different. For example, the community of OTUs unique to the floodwaters of vegetative stage plants was dominated by Gammaproteobacteria (34.5\%), Alphaproteobacteria (18.4\%), and Betaproteobacteria (10.8\%) (Figure $4(\mathrm{c})$ ). Of significance, $24.6 \%$ of the amplicon reads derived from OTUs exclusively associated with the vegetative stage could not be conclusively assigned to the class level (Figure 4(c)). In contrast, the community of OTUs unique to floodwaters of reproductive stage plants was dominated by Gammaproteobacteria (43.9\% of the amplicon reads), Bacilli (25.4\%), Clostridia (21.8\%), and Betaproteobacteria (17.7\%) (Figure 4(d)).

Of the 169 genera identified in the two developmental rice stages, 22 (13\%) occurred in both stages (Figure 5). Beijerinckia, Curvibacter, Pelomonas, and Rhodoferax occurred in high counts in both phenological stages. In general, the abundances of Beijerinckia, Pelomonas, and Rhodoferax were similar in flood waters from both communities; however, the relative abundance of Curvibacter was slightly higher in vegetative stage. The abundances of the genera Aeromonas, Bradyrhizobium, Emticicia, Massilia, Methylibium, and Spirosoma were lower and did not differ significantly between vegetative and reproductive stages (Figure 5). 


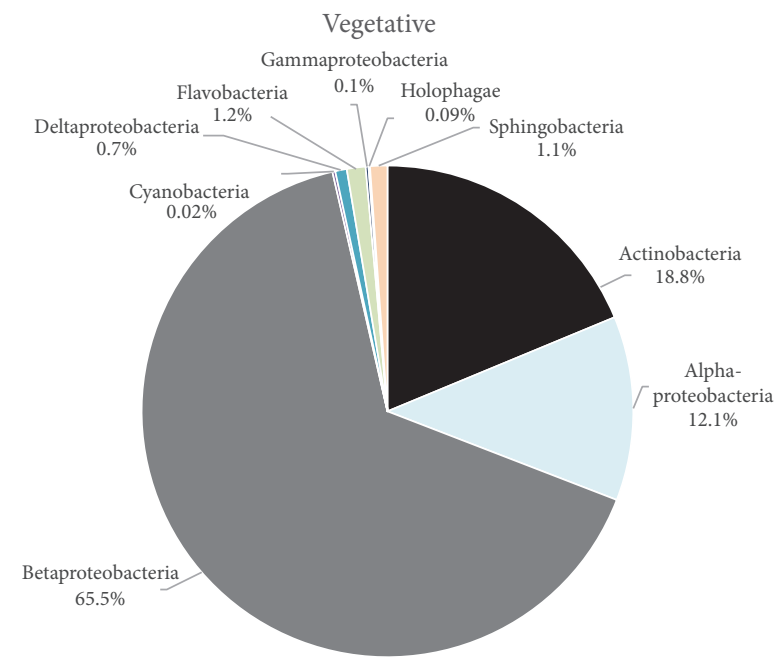

(a)

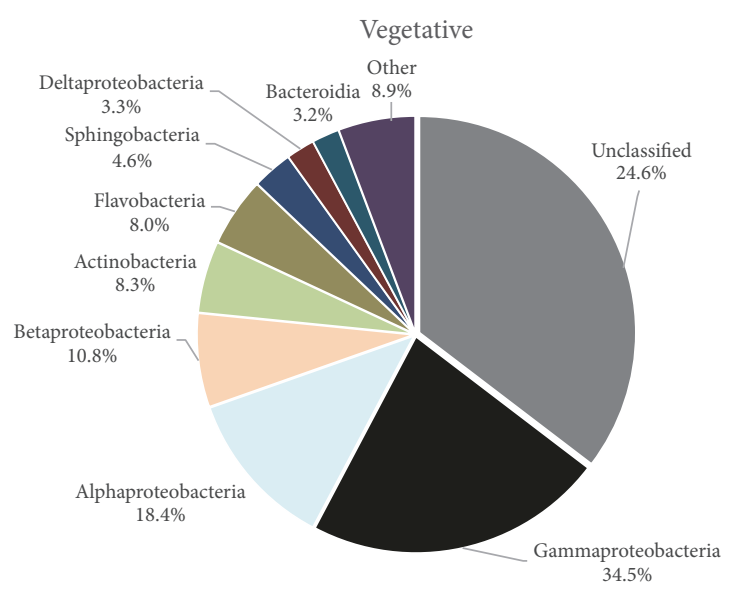

(c)

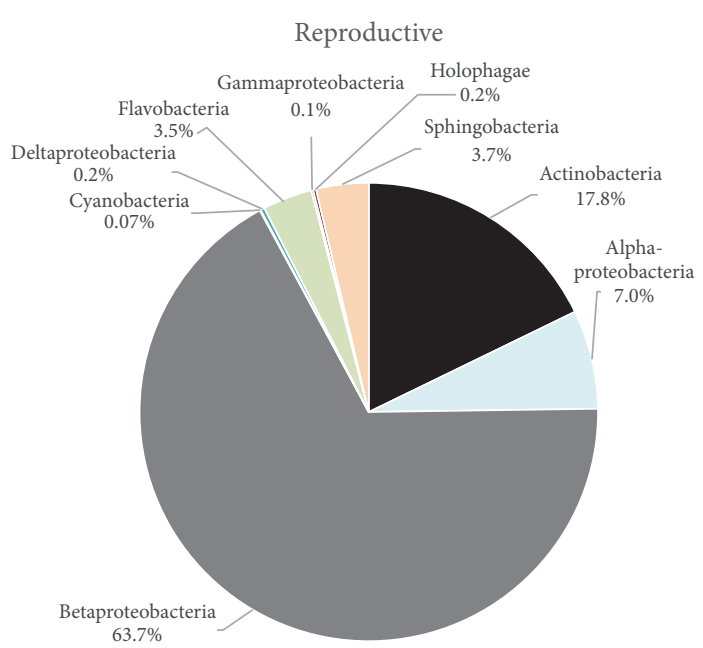

(b)

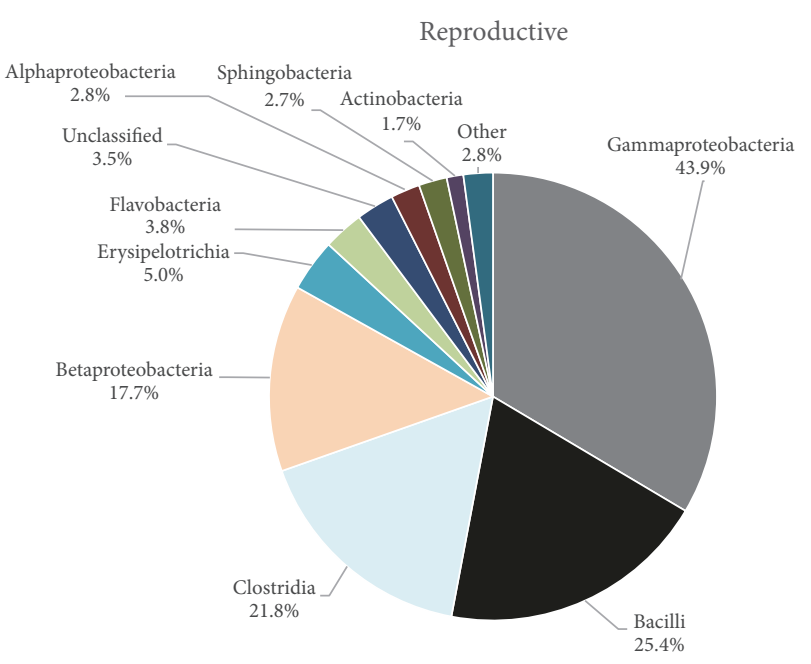

(d)

FIgURE 4: Relative abundances of class level assignments for the 88 shared OTUs in the vegetative stage (a) and reproductive stage (b) and relative abundances of the class level assignments of the 1463 OTUs unique to the vegetative stage (c) and the 515 OTUs unique to the reproductive stage $(\mathrm{d})$. OTUs were taxonomically classified by the Wang method in mothur using an $80 \%$ confidence threshold for class level assignments.

Figure 5 shows a comparative analysis of the twenty-two most abundant bacterial genera detected in the reproductive and vegetative stages of flooded rice.

Polynucleobacter (29.5\%), Curvibacter (23\%), and Rhodoferax $(10.3 \%)$ represented the most abundant genera in the vegetative stage, while Curvibacter (18.3\%), Alcaligenes (11.8\%), and Flavobacterium (11.3\%) were more abundant in the reproductive stage (Figure 6).

The Shannon-Wiener $\left(\mathrm{H}^{\prime}\right)$ index was approximately $25 \%$ higher in the water sample collected from the vegetative stage compared to the reproductive stage, suggesting that the vegetative community is richer. In addition, the Simpson index, which represents the probability that two reads selected at random belong to the same OTU, was higher in the sample collected from the reproductive stage. This finding is probably due in part to the lower richness associated with the reproductive stage, the higher number of rare OTUs found in the vegetative stage, and the overabundance of three genera, Alcaligenes, Curvibacter, and Flavobacterium in the reproductive stage. The Chao 1 richness estimator predicted a total of 2,282 OTUs in the vegetative bacterial community (32\% more OTUs than what were detected), while 822 OTUs were predicted in the reproductive bacterial community $(27 \%$ more OTUs than what were detected). Considering these results, it is clear that a larger number of rare species were associated with water collected from the vegetative stage compared to the reproductive stage (Table 2).

Reflecting the higher richness and higher numbers of rare OTUs, the rarefaction curve of the vegetative stage did not reach complete saturation considering the number 


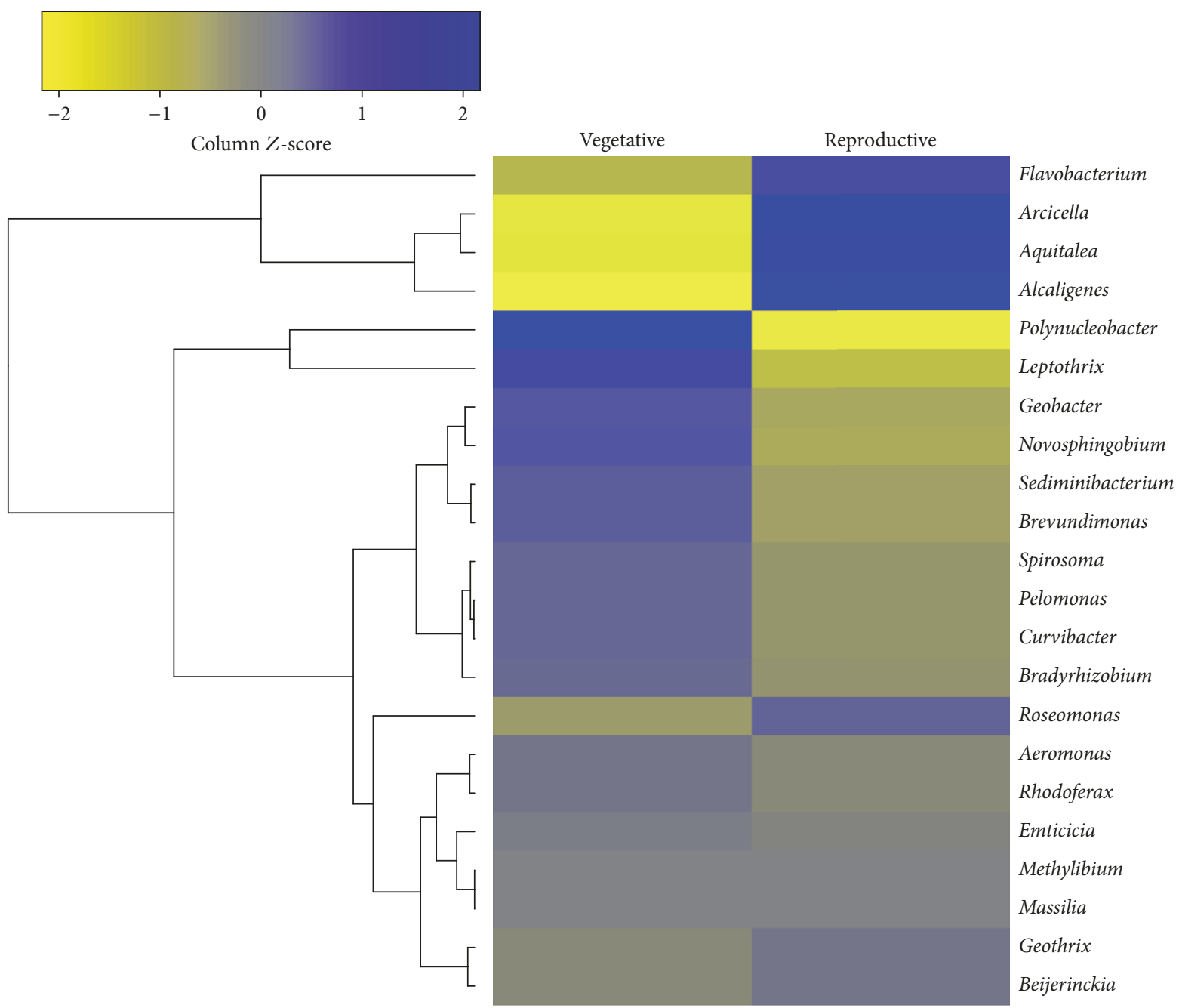

FIGURE 5: Heatmap and correlation analysis of the 22 bacterial genera found in both the vegetative and reproductive stages of flooded rice. The relative abundances of these genera in floodwaters associated with each developmental stage were $\log _{2}$ transformed, scaled by $z$-score, and used for clustering and heatmap analysis. Color intensity is correlated with the relative abundance of each genus in floodwaters associated with the two developmental stages, with blue indicating higher relative abundance and yellow indicating lower relative abundance.

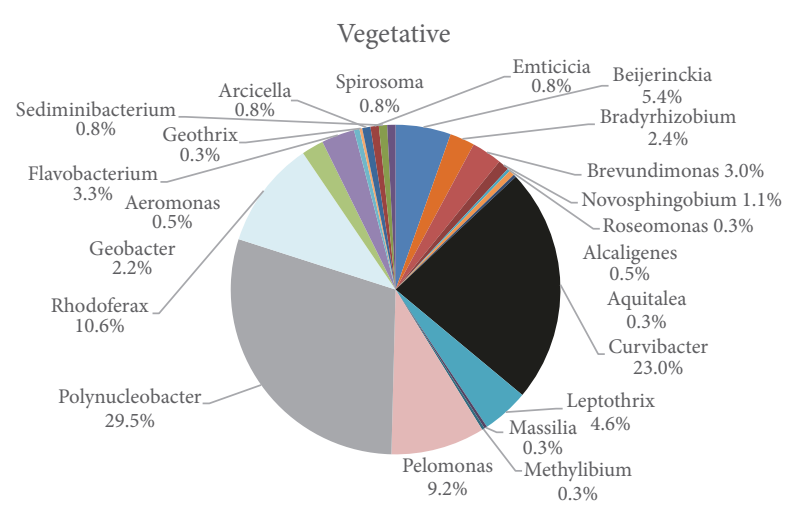

(a)

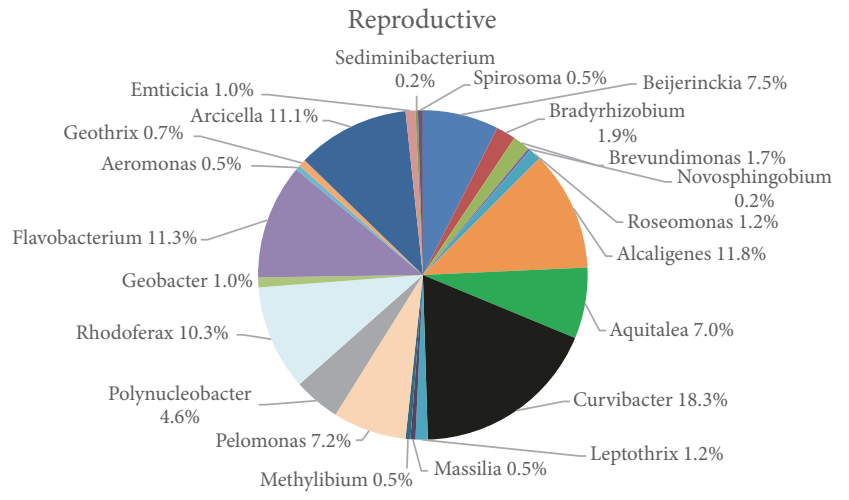

(b)

FIGURE 6: Relative abundances of genus level assignments for the OTUs shared between vegetative stage (a) and reproductive stage (b). 


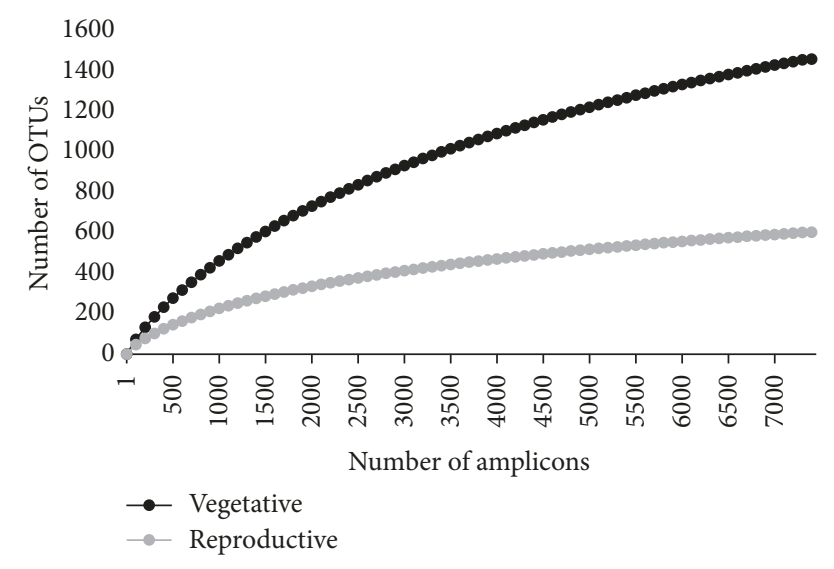

FIGURE 7: Rarefaction curves generated from 16 S amplicons sampled from floodwaters from vegetative and reproductive rice stages. Rarefaction curves were generated using the rarefaction.single command in mothur with freq $=100$ and iters $=10000$.

of sequences sampled, indicating that additional OTUs will likely be detected with additional sequencing. On the other hand, rarefaction curve of the reproductive stage showed stabilization, indicating that the sequencing effort was sufficient to capture the majority of the OTUs associated with this community (Figure 7).

\section{Discussion}

In flooded rice, the water source used for cultivation is a key component in the management of the crop. Nutrient levels in these water sources can have significant effects on plant nutrition [28] while varying physical and chemical properties in these water sources can also influence the structure, diversity, and taxonomic composition of microbial communities in the floodwaters, which in turn can also profoundly impact plant nutrition. In the rice field plots used for this study, the primary water source contains a high proportion of wastewater input from both urban and agricultural areas [29]. Therefore, a variety of chemical elements enter the floodplain and the temporal fluctuations in the abundance and types of chemical elements entering the fields can have strong influences on the microbial community in rice floodwaters [30].

In the current study, the water samples retrieved from vegetative and reproductive stages showed variations in physical and chemical parameters. The abiotic parameters most strongly associated with the vegetative stage were $\mathrm{pH}, \mathrm{P}$, and $\mathrm{K}$ and in the reproductive stage, the parameters were temperature and turbidity (Table 1). Of these parameters, temperature (higher in floodwaters from the reproductive stage) and $\mathrm{K}$ (higher in floodwaters from the vegetative stage) differed significantly between the two rice development stages. These results reflect differences in microenvironments between the rice plant-phenological stages that may have affected microbial growth and persistence. Supporting the possible impact of these environmental conditions on bacterial communities, significant differences in community composition were observed between the vegetative and reproductive stages of flooded rice, with the diversity and richness values associated with the vegetative stage exceeding those observed in the reproductive stage. Previous research on rice crops reported that the richness and diversity of bacterial communities can change throughout the rice cultivation period in aquatic environments [31-33] and in the soil and rhizosphere environments [34-36]. Although previous studies did not elucidate the environmental factors responsible for these changes in community structure, floodwater characteristics, such as $\mathrm{pH}$, temperature, changes in nutrient profiles, and seasonal variations in fertilizer application, have been related to shifts in microbial community structure and composition over crop development [32]. Additional factors related to plant growth can also cause shifts in microbial communities. For example, Okabe and coworkers [31] determined that plant growth varies with the incidence of sun light, which, in turn, can impact the water temperature and algal growth. Higher photosynthesis rates associated with algal proliferation and also plant growth [34] can ultimately lead to increased levels of photosynthates in the water, altering the water $\mathrm{pH}$ and potentially altering the bacterial community.

A total of 2,066 OTUs at 3\% dissimilarity were identified in floodwaters collected from the reproductive and vegetative developmental stages of rice. In flooded rice systems, the short spacing between the plants, the low depth of the floodwaters $(10 \mathrm{~cm}$ deep), and soil management regimes can increase the levels of suspended soil particles in the floodwaters [37], which is in contrast to other more static aquatic ecosystems. Due to the high turbidity and the presence of soil in the floodwaters, it is expected that bacterial groups associated with soil, such as Proteobacteria, Bacteroidetes, Actinobacteria, and Firmicutes, will be present in the floodwaters of rice fields, contributing to the total bacterial diversity [38]. Supporting this hypothesis, the major phyla identified in the floodwaters associated with both developmental stages were Proteobacteria, Bacteroidetes, Actinobacteria, and Firmicutes, while Acidobacteria and Cyanobacteria were less frequent. The same phyla were highly abundant in other rice habitats [7], and specifically in water samples collected from flooded rice crops $[3,32,39]$. Furthermore, Proteobacteria (alpha- and beta-subdivision), Bacteroidetes, and Actinobacteria were also cited as the major groups of bacteria found in freshwater environments [39]. In unstable environments, such as rice fields, Proteobacteria may contribute to the growth, development, and physiology of rice plants due to the presence of plant growthpromoting bacteria, which are often able to induce callus in rice and produce phytohormones [40]. According to Mhuantong et al. [16], the presence of these bacterial groups in a variety of freshwater ecosystems is related to their metabolic plasticity to decompose an assortment of organic matter.

Despite the presence of several common phyla in floodwaters sampled from both developmental stages, only 88 $(4.08 \%)$ of the OTUs were common between vegetative and reproductive stages, suggesting that the dynamics of the bacterial communities in floodwaters change throughout the growing season. These changes could reflect temporal variations in carbon availability. For example, in a previous study, 
Aulakh and coworkers [41] documented higher exudation rates over the course of rice plant development, in which sugars in the exudates were eventually replaced by organic acids in later developmental stages. Both sugars and organic acids are essential for bacterial nutrition and contribute to the process of microbial colonization [42]. Furthermore, when soluble carbon is released into the rhizosphere, microbes in the soil quickly mineralize the available carbon [43]. Thereby, the amount of root exudates in the soil could affect the relative amounts of carbon and nitrogen available for microbial growth [44], promoting transitions in the size of populations and structure of microbial communities in the rhizosphere [45]. Nevertheless, the composition and quantity of exudates are dynamic in time and space, and therefore it becomes difficult to resolve the role of a single component in the structure of microbial community [46].

The richest bacterial classes found in the vegetative stage were Gammaproteobacteria (276 OTUs), Alphaproteobacteria (237 OTUs), and Betaproteobacteria (211 OTUs), while richness was the highest in Gammaproteobacteria (24 OTUs), followed by Bacilli (46 OTUs) and Clostridia (18 OTUs) during the reproductive stage. In flooded plains, the adherence of Betaproteobacteria representatives to particles can play an important role in their transport from the terrestrial environment to floodwater [47], while the rice phyllosphere is greatly colonized by Alphaproteobacteria class [48]. Thus, Beta- and Alphaproteobacteria represent relevant bacteria groups in the soil whose abundances are strongly linked to carbon supply [49]. In flooded rice systems, these bacterial groups decompose organic matter derived from rice straw and other fermentable crop residues along with fertilizer where organic molecules (humic substances) can act as an electron donor during microbial respiration [47].

Gammaproteobacteria were present in high richness and abundance in floodwaters associated with both rice developmental stages. Overall, members from the phylum Proteobacteria are often the most abundant freshwater prokaryotes, but Gammaproteobacteria are usually present in low or transient abundances [38], although they were previously found in high amounts in the rice phyllosphere [40]. This finding suggests that specific environmental factors associated with the rice agroecosystem, such as the source of water used to irrigate the fields and the turbidity of the floodwaters, provided conditions for the survival and persistence of members of this phylum with the entrance of nutrients. This class hosts the genera Escherichia, Salmonella, Yersinia, Vibrio, and Pseudomonas characterized by their metabolic plasticity that can be adapted to varying levels of temperature, oxygen supply, and nutritional requirements. Hence, members of the class Gammaproteobacteria often dominate microbial assemblages after nutrient enrichment [50]. In addition, the members of this group contain pathways for degradation of carbohydrates, amino acids, and xenobiotics that may provide competitive advantages under certain ecological condition [51]. Furthermore, the interaction between Gammaproteobacteria members and rice plants may be beneficial to both parties, with the leaf exudates providing nutrients that support microbial growth and microorganisms assisting better rice yield [40].
Beijerinckia, Curvibacter, Pelomonas, and Rhodoferax were the four most abundant genera in both stages of the crop. These bacterial groups are often associated with high availabilities of sugar (e.g., glucose) [52]. In agricultural and freshwater environments, Beijerinckia are reported as growth promoters in plants [53], while the genomes of Curvibacter spp. often code for large numbers of sugar transporters [54], enhancing its ability to explore nutrients from the environment. Other genera, such as Pelomonas sp. and Rhodoferax sp., were found in approximately the same proportion in both rice stages. Previous rDNA 16S amplicon analysis showed that Rhodoferax spp. are common in diverse freshwater systems [55]. Some species of the genera Rhodoferax are nitrate-reducers [56], while Pelomonas spp. often code for machinery required for nitrogen fixation (nifH gene) [57]. Thus, the OTUs assigned to these genera in the current study may contribute to nitrogen flux in flooded rice fields. In contrast, the abundance of the genus Polynucleobacter differed significantly in floodwaters from the two life stages. Its abundance was significantly higher in the vegetative stage (29.5\%) compared to reproductive stage (4.6\%). This result could suggest that the OTUs derived from this genus are not well adapted to environmental conditions associated with floodwaters collected from reproductive stage plants. Polynucleobacter members often dominate planktonic freshwater communities [58], where $\mathrm{pH}$, conductivity, and dissolved organic carbon concentration play an important role in colonization [59]. Also, flagellate grazing and the consumption of low molecular weight substrates are related to the survival of Polynucleobacter in freshwater environments $[60,61]$.

Rises in temperature can increase the abundance of prokaryotes of the natural communities by enhancing their growth rates [62]. The abundance of the phylum Firmicutes (5.52\%) found in the reproductive stage is consistent with the abundance of this phylum commonly found in the rice fields [63]. However, the presence of these spore-forming populations in the reproductive stage may be related to the characteristics of the organic matter available associated with this developmental stage [63] which may vary from straw residues and root residues [64]. Species belonging to the class Clostridia are able to express enzymes that degrade the cellulose and sugar transport systems to quickly uptake sugars released from plant cell walls [65]. In rice field soil, these organisms were responsible for the decomposition of straw residue at 15 and $30^{\circ} \mathrm{C}$ [64]. From this basis, conditions found in reproductive stage such as the high temperature and carbon available to be degraded may have promoted the proliferation of OTUs belonging to Gammaproteobacteria and Firmicutes.

Rhizodeposition occurs continuously during the lifetime of plants in the form of water soluble exudates, secretions, and plant dead cells. This process contributes as a primary source of energy and nutrients for microbes in the floodwaters [66]. In future studies, the release of carbon compounds from rice roots should be considered in the investigation of the factors responsible for shaping the structure of the bacterial communities in floodwaters of rice systems [34]. With respect to environmental and nutritional conditions during the vegetative stage, approximately $20 \%$ of the absorbed 
photosynthetic carbon is released through rhizodeposition [67]. Moreover, during the reproductive stage, the plants release lower amounts of carbon compounds in their exudates because they devote the majority of their energy to seed production [68,69]. Breidenbach and Conrad [7] investigated the bacterial community of the soil from rice fields using $16 \mathrm{~S}$ rDNA amplicon analysis and also profiled the expression level of various taxa throughout the vegetative, reproductive, and maturation stages. According to quantitative PCR, the authors detected elevated bacterial abundances in soil from the reproductive stage, but there were no major differences between the bacterial community compositions during the two growth stages. Changes in bacterial abundance between soil collected from the vegetative and reproductive stages were strongly attributed to decreased levels of root exudates by plants nearing maturity. In general, the abundance of bacteria in the soil was dynamic throughout the development of rice plants; however, no microbial taxa appeared to be exclusively associated with a particular stage of development.

Heterotrophic microorganisms, which represent a large portion of the rice field microbiome [70, 71], are dependent on carbon substrates for their energy supply. The vegetative stage (tillering) is the most vigorous growth period of the rice plant [72]. As plant biomass and growth increase, intensifications of organic carbon secretions can also occur [73]. Thus, considering that the higher carbon levels could support the persistence of a larger diversity of microbes, the higher levels of exudates could contribute to the higher richness observed in this study in floodwaters collected from vegetative stage. Moreover, the use of urea in fertilizers, which is applied mainly during the vegetative stage, can affect the concentrations of available nutrients, especially $\mathrm{NH}_{4}{ }^{+}$, which is the main form of available $\mathrm{N}$ in the soil [74]. These factors, alone or in combination, may have helped to shape the bacterial communities, increasing its diversity in the vegetative stage of crop. In that sense, the release of root exudates can influence the dynamics of bacterial communities during crop development and should be investigated as a contributor to bacterial community dynamics in rice floodwaters.

\section{Conclusion}

This study revealed that the communities associated with rice floodwaters were variable and differed between floodwaters from the vegetative and reproductive stages of rice. The higher bacterial richness observed in floodwaters associated with vegetative plants may have been favored by the higher concentration of nutrients (for example, phosphorus and potassium) due to changes in rhizodeposition and crop management. OTUs from the phylum Proteobacteria were present in floodwaters collected from both developmental stages, indicating the persistence of this phylum in flooded rice ecosystems. Moreover, the predominance of the class Gammaproteobacteria and the occurrence of the phylum Firmicutes in the reproductive stage demonstrated that the environment was favorable to microbes that can persist longer in paddy fields where they are able to utilize the degradable fraction of organic materials and survive in waterlogged and dry conditions. However, further investigations regarding the composition and quantification of root exudates and the impacts of rice exudates on microbial communities in rice fields are essential to decipher the linkage between the microbial community dynamics and rice plant over cultivation time.

\section{Disclosure}

The U.S. Department of Agriculture, Agricultural Research Service, is an equal opportunity/affirmative action employer and all agency services are available without discrimination. Mention of commercial products and organizations in this manuscript is solely to provide specific information. It does not constitute endorsement by USDA-ARS over other products and organizations not mentioned.

\section{Conflicts of Interest}

The authors declare that there are no conflicts of interest regarding the publication of this paper.

\section{Acknowledgments}

The authors would like to thank CAPES (Coordenação de Aperfeiçoamento de Pessoal de Nível Superior) for the Sandwich Ph.D. Program [Grant no. 260213-0] and USDA (United States Department of Agriculture) for the financial support.

\section{References}

[1] IRRI - International Rice Research Institute, "Rice in America Latine, past, present, and promising future," Rice Today, vol. 14, pp. 1-23, 2015.

[2] GRiSP - Global Rice Science Partnership, "Rice almanac," Los Baños, Philippines: International Rice Research Institute, 2012.

[3] T. Shibagaki-Shimizu, N. Nakayama, Y. Nakajima, K. Matsuya, M. Kimura, and S. Asakawa, "Phylogenetic study on a bacterial community in the floodwater of a Japanese paddy field estimated by sequencing $16 \mathrm{~S}$ rDNA fragments after denaturing gradient gel electrophoresis," Biology and Fertility of Soils, vol. 42 , no. 4, pp. 362-365, 2006.

[4] A. E. Bernhard, D. Colbert, J. McManus, and K. G. Field, "Microbial community dynamics based on 16S rRNA gene profiles in a Pacific Northwest estuary and its tributaries," FEMS Microbiology Ecology, vol. 52, no. 1, pp. 115-128, 2005.

[5] A. R. Lopes, C. M. Manaia, and O. C. Nunes, "Bacterial community variations in an alfalfa-rice rotation system revealed by $16 \mathrm{~S}$ rRNA gene 454-pyrosequencing," FEMS Microbiology Ecology, vol. 87, no. 3, pp. 650-663, 2014.

[6] J. Zhao, T. Ni, W. Xun et al., "Influence of straw incorporation with and without straw decomposer on soil bacterial community structure and function in a rice-wheat cropping system," Applied Microbiology and Biotechnology, vol. 101, no. 11, pp. 4761-4773, 2017.

[7] B. Breidenbach and R. Conrad, "Seasonal dynamics of bacterial and archaeal methanogenic communities in flooded rice fields and effect of drainage," Frontiers in Microbiology, vol. 5, article $752,2014$.

[8] B. Breidenbach, M. B. Blaser, M. Klose, and R. Conrad, "Crop rotation of flooded rice with upland maize impacts the resident 
and active methanogenic microbial community," Environmental Microbiology, vol. 18, no. 9, pp. 2868-2885, 2016.

[9] D. E. Koeck, A. Pechtl, V. V. Zverlov, and W. H. Schwarz, "Genomics of cellulolytic bacteria," Current Opinion in Biotechnology, vol. 29, pp. 171-183, 2014.

[10] H. Itoh, S. Ishii, Y. Shiratori et al., "Seasonal transition of active bacterial and archaeal communities in relation to water management in paddy soils," Microbes and Environments, vol. 28, no. 3, pp. 370-380, 2013.

[11] Y.-J. Li, X. Chen, I. H. Shamsi, P. Fang, and X.-Y. Lin, "Effects of Irrigation Patterns and Nitrogen Fertilization on Rice Yield and Microbial Community Structure in Paddy Soil," Pedosphere, vol. 22, no. 5, pp. 661-672, 2012.

[12] I. Loaces, L. Ferrando, and A. F. Scavino, "Dynamics, Diversity and Function of Endophytic Siderophore-Producing Bacteria in Rice," Microbial Ecology, vol. 61, no. 3, pp. 606-618, 2011.

[13] J. Prakamhang, K. Minamisawa, K. Teamtaisong, N. Boonkerd, and N. Teaumroong, "The communities of endophytic diazotrophic bacteria in cultivated rice (Oryza sativa L.)," Applied Soil Ecology, vol. 42, no. 2, pp. 141-149, 2009.

[14] R. de Souza, A. Beneduzi, A. Ambrosini et al., "The effect of plant growth-promoting rhizobacteria on the growth of rice (Oryza sativa L.) cropped in southern Brazilian fields," Plant and Soil, vol. 366, no. 1-2, pp. 585-603, 2013.

[15] A. F. Scavino, J. Menes, L. Ferrando, and S. Tarlera, "Bacterial community analysis of the water surface layer from a riceplanted and an unplanted flooded field," Brazilian Journal of Microbiology, vol. 41, no. 2, pp. 411-419, 2010.

[16] W. Mhuantong, S. Wongwilaiwalin, T. Laothanachareon et al., "Survey of microbial diversity in flood areas during Thailand 2011 flood crisis using high-throughput tagged amplicon pyrosequencing," PLoS ONE, vol. 10, no. 5, Article ID e0128043, 2015.

[17] P. A. Counce, T. C. Keisling, and A. J. Mitchell, "A uniform, objectives, and adaptive system for expressing rice development," Crop Science, vol. 40, no. 2, pp. 436-443, 2000.

[18] A. D. Eaton, L. S. Clesceri, A. E. Greenberg, and M. A. H. Franson, Standard Methods for the Examination of Water and Wastewater, APHA-AWWA-WPCF, Washington, DC, USA, 1998.

[19] J. G. Caporaso, C. L. Lauber, W. A. Walters et al., "Global patterns of 16S rRNA diversity at a depth of millions of sequences per sample," Proceedings of the National Acadamy of Sciences of the United States of America, vol. 108, no. 1, pp. 4516-4522, 2011.

[20] M. J. Tedesco, C. Gianello, C. A. Bissani, H. Bohnen, and S. J. Volkweiss, Análise de Solo, Plantas e Outros Materiais, Departamento de Solos da Universidade Federal do Rio Grande do Sul, Porto Alegre, Brazil, 1995.

[21] L. Bortolon and C. Gianello, "Simultaneous multielement extraction with the mehlich-1 solution for southern Brazilian soils determined by ICP-OES and the effects on the nutrients recommendations to crops," Revista Brasileira de Ciência do Solo, vol. 34, no. 1, pp. 125-132, 2010.

[22] P. D. Schloss, S. L. Westcott, T. Ryabin et al., "Introducing mothur: open-source, platform-independent, community-supported software for describing and comparing microbial communities," Applied and Environmental Microbiology, vol. 75, no. 23, pp. 7537-7541, 2009.

[23] C. Quince, A. Lanzén, T. P. Curtis et al., "Accurate determination of microbial diversity from 454 pyrosequencing data," Nature Methods, vol. 6, no. 9, pp. 639-641, 2009.
[24] "Silva reference files (release 123)," http://www.mothur.org/ wiki/Silva_reference_files, 2017.

[25] R. C. Edgar, B. J. Haas, J. C. Clemente, C. Quince, and R. Knight, "UCHIME improves sensitivity and speed of chimera detection," Bioinformatics, vol. 27, no. 16, pp. 2194-2200, 2011.

[26] A. Chao, R. L. Chazdon, and T. J. Shen, "A new statistical approach for assessing similarity of species composition with incidence and abundance data," Ecology Letters, vol. 8, no. 2, pp. 148-159, 2005.

[27] J. Oksanen, R. Kindt, P. Legendre, B. O’Hara, and M. H. H. Stevens, “The vegan package," https://r-forge.r-project.org/ projects/vegan/, 2007.

[28] M. Diel, R. M. V. Castilhos, R. O. De Sousa, L. C. Valh, and J. B. Da Silva, "Nutrients in the water for irrigation of rice in the South region of the State of Rio Grande do Sul, Brazil," Ciência Rural, vol. 37, no. 1, pp. 102-109, 2007.

[29] S. L. Machado, E. Marchezan, A. A. Righes, R. Carlesso, S. C. Villa, and E. R. Camargo, "Consumo de água e perdas de nutrientes e de sedimentos na água de drenagem inicial do arroz irrigado," Ciência Rural, vol. 36, no. 1, pp. 65-71, 2006.

[30] D. Alongi, "The role of bacteria in nutrient recycling in tropical mangrove and other coastal benthic ecosystems," in Ecology and Conservation of Southeast Asian Marine and Freshwater Environments Including Wetlands. Developments in Hydrobiology, A. Sasekumar, N. Marshall, and D. J. Macintosh, Eds., pp. 19-32, Springer, Dordrecht, Netherlands, 1994.

[31] A. Okabe, K. Toyota, and M. Kimura, "Seasonal variations of phospholipid fatty acid composition in the floodwater of a japanese paddy field under a long-term fertilizer trial," Soil Science \& Plant Nutrition, vol. 46, no. 1, pp. 177-188, 2000.

[32] L. Barreiros, C. M. Manaia, and O. C. Nunes, "Bacterial diversity and bioaugmentation in floodwater of a paddy field in the presence of the herbicide molinate," Biodegradation, vol. 22, no. 2, pp. 445-461, 2011.

[33] N. Nakayama, A. Okabe, K. Toyota, M. Kimura, and S. Asakawa, "Phylogenetic distribution of bacteria isolated from the floodwater of a Japanese paddy field," Soil Science \& Plant Nutrition, vol. 52, no. 3, pp. 305-312, 2006.

[34] Y. Lu, A. Watanabe, and M. Kimura, "Contribution of plantderived carbon to soil microbial biomass dynamics in a paddy rice microcosm," Biology and Fertility of Soils, vol. 36, no. 2, pp. 136-142, 2002.

[35] Q. Hussain, G. X. Pan, Y. Z. Liu et al., "Microbial community dynamics and function associated with rhizosphere over periods of rice growth," Plant, Soil and Environment, vol. 58, pp. 55$61,2012$.

[36] H. J. Lee, S. Y. Kim, P. J. Kim, E. L. Madsen, and C. O. Jeon, "Methane emission and dynamics of methanotrophic and methanogenic communities in a flooded rice field ecosystem," FEMS Microbiology Ecology, vol. 88, no. 1, pp. 195-212, 2014.

[37] E. Fernández-Valiente and A. Quesada, "A shallow water ecosystem: Rice-fields. The relevance of cyanobacteria in the ecosystem," Limnetica, vol. 23, no. 1-2, pp. 95-108, 2004.

[38] Y. Wang, H. F. Sheng, Y. He et al., "Comparison of the levels of bacterial diversity in freshwater, intertidal wetland, and marine sediments by using millions of illumina tags," Applied and Environmental Microbiology, vol. 78, no. 23, pp. 8264-8271, 2012.

[39] S. Asakawa and M. Kimura, "Comparison of bacterial community structures at main habitats in paddy field ecosystem based on DGGE analysis," Soil Biology \& Biochemistry, vol. 40, no. 6, pp. 1322-1329, 2008. 
[40] G. Ren, H. Zhang, X. Lin, J. Zhu, and Z. Jia, "Response of phyllosphere bacterial communities to elevated $\mathrm{CO}_{2}$ during rice growing season," Applied Microbiology and Biotechnology, vol. 98, no. 22, pp. 9459-9471, 2014.

[41] M. S. Aulakh, R. Wassmann, C. Bueno, J. Kreuzwieser, and H. Rennenberg, "Characterization of root exudates at different growth stages of ten rice (Oryza sativa L.) cultivars," The Journal of Plant Biology, vol. 3, no. 2, pp. 139-148, 2001.

[42] B. Lugtenberg and F. Kamilova, "Plant-growth-promoting rhizobacteria," Annual Review of Microbiology, vol. 63, pp. 541-556, 2009.

[43] D. L. Jones, A. Hodge, and Y. Kuzyakov, "Plant and mycorrhizal regulation of rhizodeposition," New Phytologist, vol. 163, no. 3, pp. 459-480, 2004.

[44] G. Gupta, J. Panwar, M. S. Akhtar, and P. N. Jha, "Endophytic Nitrogen-Fixing Bacteria as Biofertilizer," Sustainable Agriculture Reviews, vol. 11, pp. 183-221, 2012.

[45] H. P. Bais, T. L. Weir, L. G. Perry, S. Gilroy, and J. M. Vivanco, "The role of root exudates in rhizosphere interactions with plants and other organisms," Annual Review of Plant Biology, vol. 57, no. 1, pp. 233-266, 2006.

[46] M. Ziegler, M. Engel, G. Welzl, and M. Schloter, "Development of a simple root model to study the effects of single exudates on the development of bacterial community structure," Journal of Microbiological Methods, vol. 94, no. 1, pp. 30-36, 2013.

[47] A. P. King, K. J. Evatt, J. Six, R. M. Poch, D. E. Rolston, and J. W. Hopmans, "Annual carbon and nitrogen loadings for a furrowirrigated field," Agricultural Water Management, vol. 96, no. 6, pp. 925-930, 2009.

[48] J. A. Vorholt, "Microbial life in the phyllosphere," Nature Reviews Microbiology, vol. 10, no. 12, pp. 828-840, 2012.

[49] J. B. Chiaramonte, M. D. C. Roberto, and T. A. Pagioro, "Seasonal dynamics and community structure of bacterioplankton in upper Paraná River floodplain," Microbial Ecology, vol. 66, no. 4, pp. 773-783, 2013.

[50] R. J. Newton and K. D. Mcmahon, "Seasonal differences in bacterial community composition following nutrient additions in a eutrophic lake," Environmental Microbiology, vol. 13, no. 4, pp. 887-899, 2011.

[51] A. C. Poot-Hernandez, K. Rodriguez-Vazquez, and E. PerezRueda, "The alignment of enzymatic steps reveals similar metabolic pathways and probable recruitment events in Gammaproteobacteria," BMC Genomics, vol. 16, no. 1, article 957, 2015.

[52] M. Ofek, Y. Hadar, and D. Minz, "Ecology of root colonizing Massilia (Oxalobacteraceae)," PLoS ONE, vol. 7, no. 7, Article ID e40117, 2012.

[53] D. S. Thuler, E. I. S. Floh, W. Handro, and H. R. Barbosa, "Plant growth regulators and amino acids released by Azospirillum sp. in chemically defined media," Letters in Applied Microbiology, vol. 37, no. 2, pp. 174-178, 2003.

[54] J. A. Chapman, E. F. Kirkness, O. Simakov et al., "The dynamic genome of Hydra," Nature, vol. 464, pp. 592-596, 2010.

[55] G. Zwart, B. C. Crump, M. P. Kamst-van Agterveld, F. Hagen, and S.-K. Han, "Typical freshwater bacteria: An analysis of available 16S rRNA gene sequences from plankton of lakes and rivers," Aquatic Microbial Ecology, vol. 28, no. 2, pp. 141-155, 2002.

[56] A. Hougardy and J.-H. Klemme, "Nitrate reduction in a new strain of Rhodoferax fermentans," Archives of Microbiology, vol. 164, no. 5, pp. 358-362, 1995.
[57] J. Terakado-Tonooka, Y. Ohwaki, H. Yamakawa, F. Tanaka, T. Yoneyama, and S. Fujihara, "Expressed nifH genes of endophytic bacteria detected in field-grown sweet potatoes (Ipomoea batatas L.)," Microbes and Environments, vol. 23, no. 1, pp. 89-93, 2008.

[58] S. Crevecoeur, W. F. Vincent, J. Comte, and C. Lovejoy, "Bacterial community structure across environmental gradients in permafrost thaw ponds: Methanotroph-rich ecosystems," Frontiers in Microbiology, vol. 6, article 192, 2015.

[59] J. Jezbera, J. Jezberová, U. Brandt, and M. W. Hahn, "Ubiquity of Polynucleobacter necessarius subspecies asymbioticus results from ecological diversification," Environmental Microbiology, vol. 13, no. 4, pp. 922-931, 2011.

[60] K. Horňák, V. Kasalický, K. Šimek, and H. Grossart, “ Strainspecific consumption and transformation of alga-derived dissolved organic matter by members of the "'Environmental Microbiology, vol. 19, no. 11, pp. 4519-4535, 2017.

[61] M. W. Hahn, T. Scheuerl, J. Jezberová et al., “The passive yet successful way of planktonic life: Genomic and experimental analysis of the ecology of a free-living polynucleobacter population," PLoS ONE, vol. 7, no. 3, Article ID e32772, 2012.

[62] D. T. A. Tuyet, T. Tanaka, R. Sohrin, D. M. Hao, K. Nagaosa, and K. Kato, "Effects of warming on microbial communities in the coastal waters of temperate and subtropical zones in the Northern Hemisphere, with a focus on Gammaproteobacteria," Journal of Oceanography, vol. 71, no. 1, pp. 91-103, 2015.

[63] A. Reim, M. Hernández, M. Klose, A. Chidthaisong, M. Yuttitham, and R. Conrad, "Response of methanogenic microbial communities to desiccation stress in flooded and rain-fed paddy soil from Thailand," Frontiers in Microbiology, vol. 8, no. MAY, article 785, 2017.

[64] J. Rui, J. Peng, and Y. Lu, "Succession of bacterial populations during plant residue decomposition in rice field soil," Applied and Environmental Microbiology, vol. 75, no. 14, pp. 4879-4886, 2009.

[65] Y. Kim and W. Liesack, "Differential assemblage of functional units in paddy soil microbiomes," PLoS ONE, vol. 10, no. 4, Article ID e0122221, 2015.

[66] J. Tian, M. Dippold, J. Pausch et al., "Microbial response to rhizodeposition depending on water regimes in paddy soils," Soil Biology \& Biochemistry, vol. 65, pp. 195-203, 2013.

[67] C. Mougel, P. Offre, L. Ranjard et al., "Dynamic of the genetic structure of bacterial and fungal communities at different developmental stages of Medicago truncatula Gaertn. cv. Jemalong line J5," New Phytologist, vol. 170, no. 1, pp. 165-175, 2006.

[68] W. X. Wu, W. Liu, H. H. Lu, Y. X. Chen, M. Devare, and J. Thies, "Use of 13C labeling to assess carbon partitioning in transgenic and nontransgenic (parental) rice and their rhizosphere soil microbial communities," FEMS Microbiology Ecology, vol. 67, no. 1, pp. 93-102, 2009.

[69] A. Zancarini, C. Lépinay, J. Burstin et al., “Combining Molecular Microbial Ecology with Ecophysiology and Plant Genetics for a Better Understanding of Plant-Microbial Communities' Interactions in the Rhizosphere," in Molecular Microbial Ecology of the Rhizosphere, F. J. D. Bruijn, Ed., vol. 1, pp. 69-86, 2013.

[70] M. H. L. R. Reche and L. M. Fiuza, "Bacterial diversity in ricefield water in Rio Grande do Sul," Brazilian Journal of Microbiology, vol. 36, no. 3, pp. 253-257, 2005.

[71] J. P. Panizzon, V. R. M. MacEdo, V. MacHado, and L. M. Fiuza, "Microbiological and physical-chemical water quality of the rice fields in Sinos River's basin, Southern Brazil," Environmental Modeling \& Assessment, vol. 185, no. 3, pp. 2767-2775, 2013. 
[72] T. Ge, H. Yuan, H. Zhu et al., "Biological carbon assimilation and dynamics in a flooded rice-soil system," Soil Biology \& Biochemistry, vol. 48, pp. 39-46, 2012.

[73] N. Fierer, C. L. Lauber, K. S. Ramirez, J. Zaneveld, M. A. Bradford, and R. Knight, "Comparative metagenomic, phylogenetic and physiological analyses of soil microbial communities across nitrogen gradients," The ISME Journal, vol. 6, no. 5, pp. 10071017, 2012.

[74] S. K. Dubey and J. S. Singh, "Spatio-temporal variation and effect of urea fertilization on methanotrophs in a tropical dryland rice field," Soil Biology \& Biochemistry, vol. 32, no. 4, pp. 521-526, 2000. 


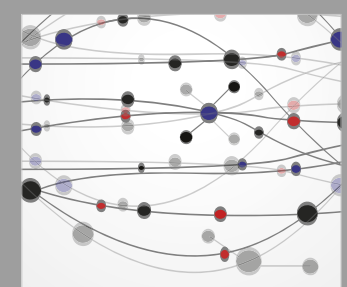

The Scientific World Journal
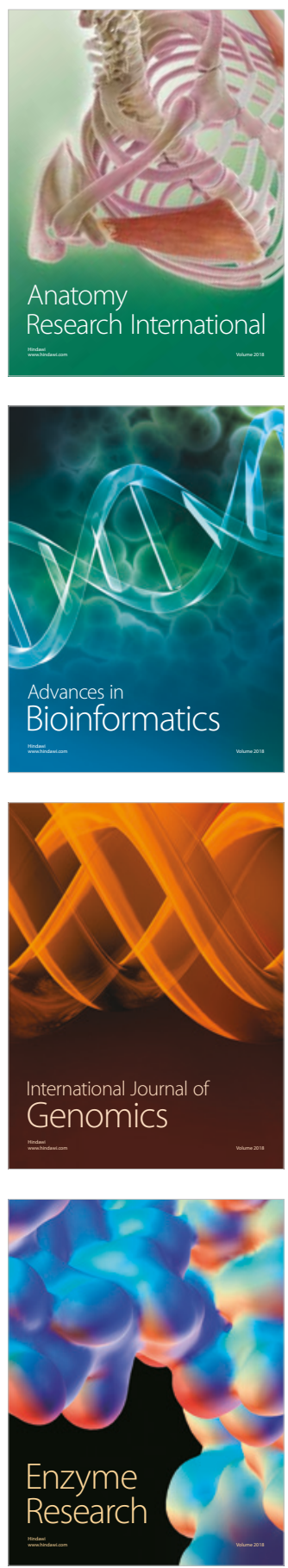
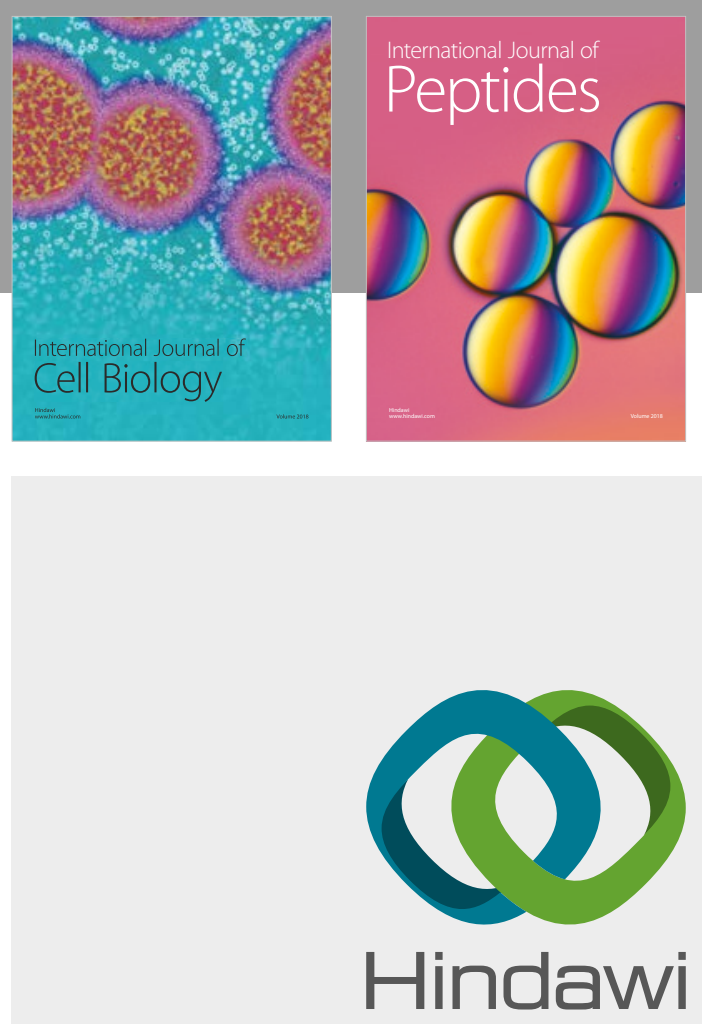

Submit your manuscripts at

www.hindawi.com
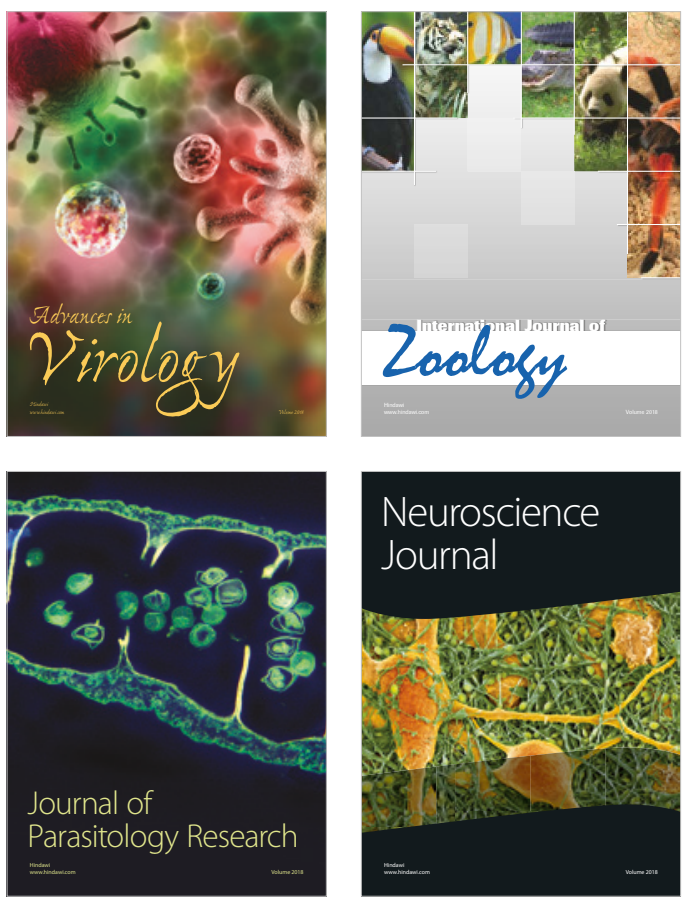
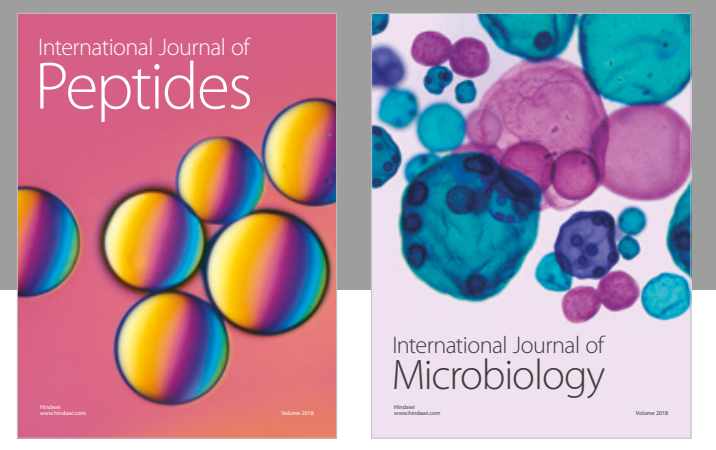

nternational Journal of Microbiology
Journal of
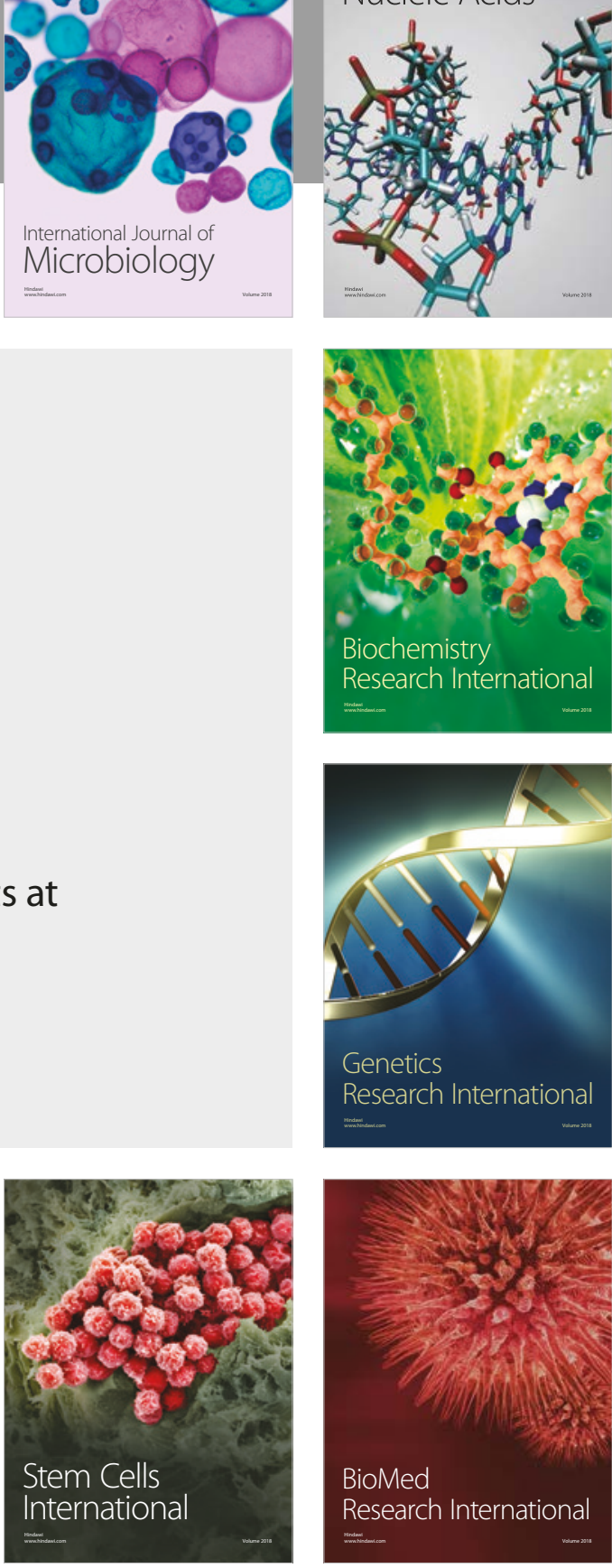
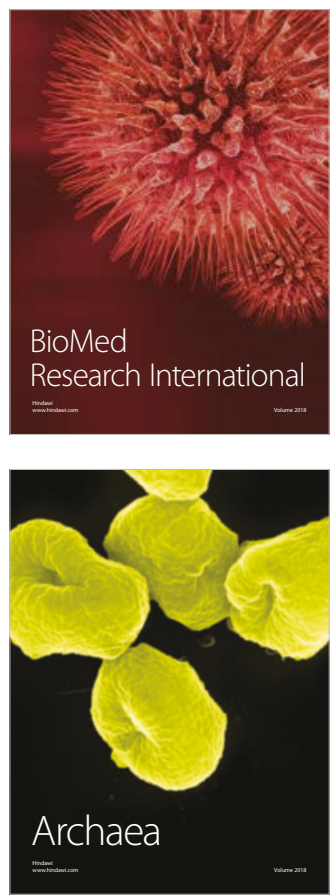